\title{
End stage renal disease as a symptom of health inequalities in French Guiana
}

\author{
Dévi Rita Rochemont ${ }^{1}$, Jean Marc Dueymes ${ }^{2}$, Raoul Roura ${ }^{3}$, Meddeb Meddeb ${ }^{4}$, Cécile Couchoud ${ }^{5}$, \\ Mathieu Nacher ${ }^{1,6}$ \\ 'Clinical Investigation Center in Clinical Epidemiology French Guiana "CIC 1424 INSERM", French Guiana \\ ${ }^{2}$ Hospital Center of Cayenne André Rosemon, French Guiana \\ ${ }^{3}$ Association Treatment of Kidney Failure in Guyana "ATIRG", French Guiana \\ 4"Véronique Kapa" Health Clinic, French Guiana \\ ${ }^{5}$ Biomedicine Agency, France \\ ${ }^{6}$ EA3593 UFR Medicine University of the West Indies and Guiana, French Guiana
}

\begin{abstract}
Objectives: French Guiana attracts numerous migrants in search of a better life. They often live in very poor conditions, and may thus have difficulties in accessing care. The objective of the study was to look at differences between French and non-French ESRD patients in French Guiana.

Material and methods: Data from REIN registry in French Guiana was used between 1 January 2011 and 31 December 2016. Data from the population census was used to compare the prevalence of ESRD between French and foreign citizens. Longitudinal data was analyzed using survival analysis. Cox proportional hazards modelling was used.

Results: Half of patients on dialysis were of foreign origin. The odds ratio of ESRD was $2.2(95 \% \mathrm{CI}=$ $1.8-2.8, p<0.0001)$ for foreigners relative to French citizens. When looking at adults only, immigrants were still more likely to have ESRD OR $=1.45$ ( $95 \% \mathrm{CI}=1.2-1.7), p<0.001$. There was a significant age difference between foreign patients with ESRD and French patients with ESRD, 58.9 years $(\mathrm{SD}=13.79$ ) vs. 62.2 years $(S D=16.03)$, respectively, $p=0.02$. No significant difference was found between French citizens and migrants regarding the underlying nephropathy, or mortality. However, when adjusting for age and looking at specific nationalities, patients from Guyana, Brazil, and the Dominican Republic, had a greater mortality.

Conclusions: Although there was no difference in prevalence between migrants and French citizens, the age at diagnosis of ESRD was lower in immigrants from neighboring countries Guyana, Suriname, and Brazil. Age-adjusted mortality was higher in some immigrant groups relative to French patients. Earlier detection of socially vulnerable patients with renal failure or with risk factors for renal failure should be a priority in French Guiana.
\end{abstract}

KEY WORDS: epidemiology, French Guiana, end stage renal failure, migrant, death, incidence.

ADDRESS FOR CORRESPONDENCE: Dévi Rita Rochemont, Centre d'Investigation Clinique Epidémiologie Clinique Antilles Guyane CIC INSERM 1424, Centre hospitalier Andrée Rosemon, Rue des flamboyants BP6006, 97306 Cayenne, French Guiana, e-mail: devi.rochemont@ch-cayenne.frIntroduction

Health inequalities remain widespread between different countries and within countries [1]. Differences in absolute and relative wealth are both important, but the latter are especially prominent $[2,3]$. Health concerns vary across social strata. There may also be differences in access to information that lead the poorest and least educated to have a different relation to health and a poorer knowledge of the health care system. Thus, health-seeking behavior in those groups tend to be late and oriented towards curative care. Finally, financial barriers 
(remaining health costs, transport, etc.) may also help account for the social inequalities in health. The reasons why patients are tested late or let serious diseases evolve without treatment are complex. Certain persons do not use the available public health-services, while for others obstacles will ultimately lead to renouncing health care despite recognizing a need for it [4]. In the USA, it was shown that the incidence of ESRD (end stage renal disease) attributed to diabetes was strongly associated with area-based measures of access to care, suggesting that difficulties in accessing care were linked to ESRD [5].

French Guiana is a French territory located in South America. The population is estimated to be 252,338 living on a territory of $83,846 \mathrm{~km}^{2}$ [6]. The GDP per capita is the highest in Latin America, which makes French Guiana attractive for numerous migrants in search of a better life. Thus, $29 \%$ of the population are foreign national [7]. Regarding the health care system, the standard of care is often much better than elsewhere in Latin America, with public funding and access to rights that are unmatched elsewhere on the continent [8]. Paradoxically, in comparison with other French territories, French Guiana faces numerous challenges [9]: it has the highest population growth rate on the continent, it has numerous socio-economic problems, a high unemployment rate, and $30 \%$ of the population who are immigrants, often live in poverty, do not speak French, and are frequently illiterate $[9,10]$. A large proportion of this population does not have a valid health insurance, which restricts their access to prevention and care.

In France, French Guiana is perceived as a wild territory still struggling with tropical diseases, snakes and insects. However, in reality there has been an epidemiologic transition from infectious diseases towards chronic diseases. The end stage renal disease registry in French Guiana has shown a high prevalence of end stage renal disease in this territory [11]. Health inequalities have been reported in French Guiana for a number of specific health problems, with migrants often having poorer outcomes than French nationals. The objective of the present study is to unmask health inequalities for migrants in accessing ESRD care within French Guiana. The ultimate aim would be to upgrade, if necessary, the detection and care of renal failure or potential causes of renal failure in order to mitigate the burden of ESRD in French Guiana.

\section{MATERIAL AND METHODS POPULATION}

Data from the cohort of patients included in the REIN (Réseau Epidémiologie et Information en Néphrologie) registry for end stage renal disease was used between 1 January 2011 and 31 December 2016 in French Guiana [12]. The study population consisted of patients receiving treatment for ESRD by either dialysis or renal transplantation followed in one of the five treatment centers in French Guiana.

\section{REIN REGISTRY DATA}

The REIN registry describes the incidence and prevalence of ESRD treated by renal replacement therapy. It also reports treatments, population characteristics, patient survival, and access to renal transplant. The registry is exhaustive for patients with end stage renal disease. The registry covers mainland France and overseas French territories which allows benchmarking and identifying epidemiologic differences. This cohort was approved by the French Regulatory authorities CNIL (Commission Nationale de l'Informatique et des Libertés authorisation $\mathrm{n}^{\circ}$ 903188) and the CCTIRS (Comité Consultative sur le traitement de l'Information en matière de Recherche dans le domaine de la Santé, authorization $\mathrm{n}^{\circ}$ 03.149).

In French Guiana, research assistants compile data from medical records at the sites treating patients with ESRD. The data includes information on the patient's socio-demographic profile, onset of renal disease, clinical condition, treatment modalities, transfer between facilities, weaning, renal transplant attempts, and death. Most patients with ESRD did not actually get a renal biopsy: 15\% of patients included between 2011 and 2016 had it. However, the diagnosis was performed after non-invasive evaluation by nephrologists (biology on blood and urine, kidney and abdominal ultrasounds, abdominal scanner, and sometimes angiography).

Demographic data came from census data by the INSEE (Institut National des Statistiques et des Etudes Economiques).

In order to infer the number of severe renal failure cases and moderate renal failure cases in French Guiana we used the estimates from the NHANES study (National Health and Nutrition Examination Surveys) [13].

Among the key study outcomes were: the prevalence of ESRD which was calculated as the number of patients with ESRD relative to the population concerned; the incidence of death among patients included in the registry, by country of origin; and the age distribution of patients with ESRD by nationality.

In order to compare the prevalence of ESRD in the French population of French Guiana with the prevalence among migrants we divided the number of French patients by the number of French persons in French Guiana according to the INSEE and compared it with the number of foreign patients divided by the total number of foreigners living in French Guiana. We also calculated the attributable risk in foreigners and in the global population of ESRD.

Longitudinal data was analyzed using survival analysis. Death was the single failure event. Kaplan-Meier curves were obtained and incidence rates were obtained. Cox proportional Hazards modelling was used to look at differences by country of origin. The proportionality of hazards was tested using Schoenfeld and scaled Schoenfeld residuals. 
Data analysis was performed using STATA 12 (STATA Corp, College Station, Texas).

\section{RESULTS}

Overall there were 434 patients, and 1034 records, with 1263 person-years at risk, 166 patients died. There were 194 foreign patients and 219 French patients, and 21 of unknown nationality. Overall, the incidence rate of ESRD was 12.6 per 100 person-years (median survival time 5.3 years).

For ESRD, nearly half (49\%) of patients starting dialysis were of foreign origin. Considering the French and foreign populations in French Guiana, the odds ratio of ESRD was thus 2.2 (95\% CI $=1.8-2.8, p<0.0001)$ for foreigners relative to French citizens. However, given the fact that most foreigners are adults we used the number of French or foreign adults as denominator. Thus, when looking at adults only, there still was a difference between French citizens and immigrants, with an odds ratio of 1.45 (95\% CI $=1.17-1.7), p<0.001$. There was a significant age difference between foreign patients with ESRD and French patients with ESRD, who were aged 58.9 years $(S D=13.79)$ vs. 62.2 years $(S D=16.03)$, respectively $(p=0.02)$.

When looking into details, the mean age for immigrants from Brazil, Guyana, Haiti and Suriname was $56.9,50.3,61$ and 56 years, respectively (Fig. 1).

When comparing the three main causes of nephropathy by French or status there was no significant difference for the cause of ESRD: hypertension (34.8.\% vs. $33.1 \%$, respectively, $p=0.69)$, diabetes $(31.6 \%$ vs. $32.2 \%$, respectively, $p=0.89$ ). However, there was a significant difference for infectious nephropathies, with foreign patients being more frequently affected $(5.1 \%$ vs. $11.2 \%$, respectively, $p=0.01$ ).

Figure 2 shows the Kaplan Meier curve for death in French Guiana and that about half of the patients died within 5 years. There was no significant difference between French citizens or migrants regarding the underlying nephropathy, or crude mortality. The hazard ratio was $1.11(95 \% \mathrm{CI}=0.81-1.53), p=0.5$. The proportional hazards assumption was fulfilled (global test, $p=0.26$ ).

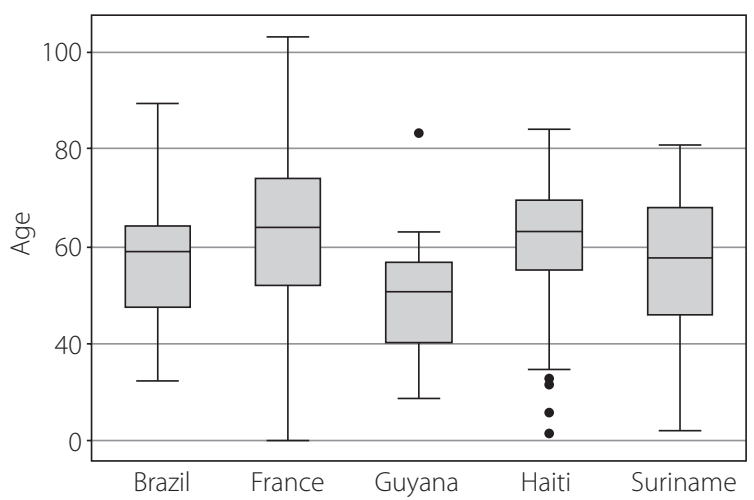

FIG. 1. Age of patients with end stage renal disease in French Guiana, by nationality

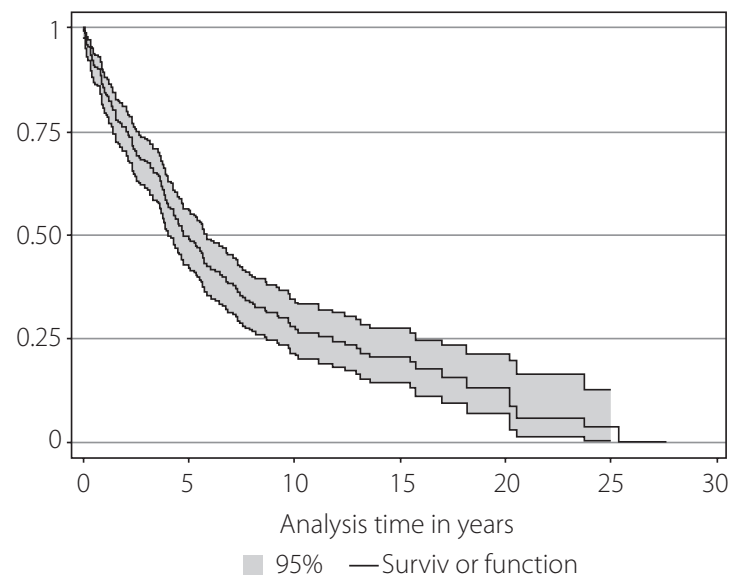

FIG. 2. Kaplan-Meier survival estimate in French Guiana

However, when adjusting for age and looking at specific nationalities, patients from Guyana, Brazil, and the Dominican Republic, seemed to have a greater mortality (Table 1).

\section{DISCUSSION}

Although half of patients on dialysis were migrants, when considering only the adult population, there was significant difference of ESRD prevalence between migrant and French patients. However, when looking at patient age, migrants with ESRD were significantly

TABLE 1. Cox proportional hazards model in French Guiana, by nationality

\begin{tabular}{|l|c|c|c|c|}
\hline Country & Time at risk & $\begin{array}{c}\text { Incidence rate } \\
\text { per } 100 \text { person-years }\end{array}$ & $\begin{array}{c}\text { Adjusted* hazard ratio } \\
(95 \% \text { CI) }\end{array}$ & $p$ \\
\hline France & 596.58 & 14.08 & 1 & 0.02 \\
\hline Brazil & 22.31 & 22.4 & $1.26(0.7-1.9)$ & 0.4 \\
\hline Haiti & 178.52 & 15.12 & $3.7(1.3-10.5)$ & 0.01 \\
\hline Guyana & 14.12 & 28.34 & $0.9(0.5-1.5)$ & 0.6 \\
\hline Suriname & 202.83 & 8.38 & $(1.3-10.6)$ & 0.01 \\
\hline Dominican Republic & 7.29 & 54.9 & & 0.01 \\
\hline
\end{tabular}

*The Cox model included age, sex and the indicator variables for nationality. 
younger than French patients with ESRD. Our interpretation of this observation is that this is a symptom of the health inequalities in French Guiana and reflects delays in accessing care. Migrants in French Guiana often live in very poor conditions, and struggle to make ends meet. Delayed access to care may result from problems with the right to access healthcare, or they may result from health seeking behavior that is mostly oriented towards curative care and not prevention or screening. Non-painful conditions such as high blood pressure or diabetes may evolve for prolonged periods and may be discovered only when complications appear, one of these complication being ESRD [14]. There were no patent differences in the causal nephropathies, but foreign patients seemed more at risk of infectious causes for kidney disease, mostly HIV, which can easily be explained by the fact that over $75 \%$ of HIV patients in French Guiana are foreigners [15].

When looking more into details, patients from Brazil, Guyana, and Suriname where younger than French patients. Patients from Haiti were not younger than French patients. There was no difference regarding the underlying cause of ESRD between migrants and French citizens. After controlling for age, some nationalities seemed to have a greater ESRD mortality rate. Persons from Guyana, Brazil, the Dominican Republic, had a greater mortality, whereas the first and second largest immigrant communities, Surinamese and Haitians, did not.

Kidney disease is often silent until late stages. Thus the majority of persons with CKD (chronic kidney disease) are unaware that they have impaired renal function [16]. In French Guiana, the proportion of persons who are unaware of their renal disease is also presumably very high, and this proportion may be even higher among immigrants. The estimation of the prevalence of earlier stages of chronic renal failure is important for disease management and prevention. In the USA, it was estimated that $16 \%$ of the adult population (over 20 million persons) had some stage of kidney failure, and that 661,648 had ESRD. Thus, in the USA, about 3.3\% of persons with CKD had ESRD. It was also estimated in the USA that most persons are unaware of having chronic kidney disease. At baseline, 9.4\% of persons with CKD knew that they had impaired renal function in 2001-2006. Among patients with CKD, it was estimated that $13 \%$ had stage $1,24 \%$ stage $2,57.5 \%$ had stage 3 and $2.6 \%$ had stage 4 renal disease [17]. If we extrapolate these proportions to French Guiana, this would mean that over 12000 patients have chronic kidney failure among whom are 1677 with stage 1, 2981 with stage 2, 7174 with stage 3 , and 326 with stage 4 renal disease, and finally 504 patients with stage 5 renal disease. This represents a very large number of patients in a territory that has very few specialist. Since the REIN registry concerns patients who have access to care, and given the specific conditions of French Guiana where a significant propor- tion of the population lives far from specialized health centers, it is likely that our registry only includes part of the ESRD cases. In addition, in French Guiana, some of the illegal immigrants are not included in the INSEEs population estimate. Thus, the prevalence of ESRD in French Guiana is probably higher than the estimates from the REIN registry.

Identifying patients with diabetes or hypertension before developing complications is challenging in the most socially vulnerable patients. However, health mediators integrated within the socially vulnerable communities have shown their usefulness in several chronic diseases at the time of screening and in subsequent phases of care. For example, if we hypothesize that a health mediator program could reduce by $25 \%$ the number of patients for whom hypertension or diabetes are discovered at the stage of complications, this would imply for ESRD only, considerable benefits in financial terms $[18,19]$.

In French Guiana, health inequalities are patent for a broad range of pathologies for all age groups, from infectious diseases to non-communicable diseases [20-25].

In all the above studies, being an immigrant is used as a proxy to poverty, vulnerability and difficulties in accessing care leading to patent health inequalities. A recent study in the poorest neighborhoods around Cayenne showed that although most persons (73.4\%) declared that it was easy to see a physician, $21 \%$ had renounced care in French Guiana [26]. However, counter-intuitively, $66.4 \%$ of persons having renounced care said it was easy to see a doctor.

In conclusion, although there was no difference in ESRD prevalence between migrants and French citizens in French Guiana, while the age at diagnosis of ESRD was younger in immigrants from neighboring countries: Guyana, Suriname, and Brazil. Age-adjusted mortality was higher in some immigrant groups relative to French patients. Efforts should be made to mitigate the burden of ESRD in French Guiana. Given the demanding minimum physical requirements of migration, it is likely that most migrants develop terminal renal failure within French Guiana and not in their country of origin. Ensuring optimal health care access for migrants with potential causes of renal failure such as diabetes or hypertension, and specialized care for those with earlier stages of renal disease, could have significant benefits.

\section{ACKNOWLEDGEMENTS}

The REIN registry is funded by "Agence de la Biomedecine (ABM)".

We acknowledge all registry participants, especially the staff of dialysis centres in French Guiana: Kapa santé Clinique Véronique, Association Traitement de l'Insuffisance Rénale en Guyane (ATIRG) and Centre the hospital Andrée Rosemon Cayenne. 


\section{DISCLOSURE}

The authors report no conflict of interest.

\section{References}

1. Marmot M. Social determinants of health inequalities. Lancet 2005; 365: 1099-1104.

2. Wilkinson RG. Socioeconomic determinants of health. Health inequalities: relative or absolute material standards? BMJ 1997; 314: 591-595.

3. Wagstaff A. Poverty and health sector inequalities. Bull World Health Organ 2002; 80: 97-105.

4. Révil H. Le non-recours aux soins de santé [Non-use of the health care system. Life of Ideas]. Vie Idées 2014. Available from: https://www.mshalpes.fr/documents/le_non-recours_ aux_soins_de_sante.pdf (accessed: 15 May 2018).

5. Ward MM. Access to care and the incidence of end-stage renal disease due to diabetes. Diabetes Care 2009; 32: 1032-1036.

6. Couillaud A. Recensement de la population en Guyane - 252338 habitants au 1er janvier 2014 [French Guiana population census] Insee 2017. Available from: https://www.insee.fr/fr/statistiques/2540209\#consulter (accessed: 15 May 2018).

7. Dossier complet - Département de la Guyane (973) [French Guiana population census] Insee 2015. Available from: https:// www.insee.fr/fr/statistiques/2011101?geo=DEP-973 (accessed: 15 May 2018).

8. OMS Rapport sur la santé dans le monde, 2000 - Pour un système de santé plus performant [WHO Global health report, 2000 - for a more effective health system] OMS 2000. Available from: http://www.who.int/whr/2000/fr/ (accessed: 15 May 2018).

9. La santé dans les outre-mer: une responsabilité de la République [Health in the overseas French territories: a responsability of the republic] française LD 2014. Available from: http://www. ladocumentationfrancaise.fr/rapports-publics/144000327/ index.shtml (accessed: 15 May 2018).

10. Enquête Information et Vie Quotidienne : Lire, écrire, compter : des savoirs fragiles en Guyane [Daily life survey: reading, writing, counting: Fragile knowledge in French Guiana] Insee 2013. Available from: https://www.insee.fr/fr/statistiques/1291999 (accessed: 15 May 2018).

11. Rochemont DR, Meddeb M, Roura R, et al. End stage renal disease in French Guiana (data from R.E.I.N registry): South American or French? BMC Nephrol 2017; 18: 207.

12. Couchoud C, Stengel B, Landais P, et al. The renal epidemiology and information network (REIN): a new registry for endstage renal disease in France. Nephrol Dial Transplant 2006; 21: 411-418.

13. Coresh J, Selvin E, Stevens LA, et al. Prevalence of chronic kidney disease in the United States. JAMA 2007; 298: 2038-2047.

14. R.E.I.N. (Réseau Epidémiologique et Information en Néphrologie) [French renal epidemiology and information network registry] - Agence de la biomédecine 2016. Available from: https://www.agence-biomedecine.fr/Le-programme-REIN (accessed: 15 May 2018).

15. Nacher M, Vantilcke V, Parriault MC, et al. What is driving the HIV epidemic in French Guiana? Int J STD AIDS 2010; 21: 359-361.
16. Coresh J, Byrd-Holt D, Astor BC, et al. Chronic kidney disease awareness, prevalence, and trends among U.S. adults, 1999 to 2000. J Am Soc Nephrol 2005; 16: 180-188.

17. Coresh J, Astor BC, Greene T, et al. Prevalence of chronic kidney disease and decreased kidney function in the adult US population: Third National Health and Nutrition Examination Survey. Am J Kidney Dis 2003; 41: 1-12.

18. Natale-Pereira A, Enard K, Nevarez L, Jones L. The role of patient navigators in eliminating health disparities. Cancer 2011; 117 (15 Suppl): 3543-3552.

19. Braun K, Thomas W, Domingo J, et al. Reducing cancer screening disparities in medicare beneficiaries through cancer patient navigation. J Am Geriatr Soc 2015; 63: 365-370.

20. Jolivet A, Cadot E, Florence S, et al. Migrant health in French Guiana: are undocumented immigrants more vulnerable? BMC Public Health 2012; 12: 53.

21. Nacher M, El Guedj M, Vaz T, et al. Risk factors for late HIV diagnosis in French Guiana. AIDS 2005; 19: 727-729.

22. Nacher M, El Guedj M, Vaz T, et al. Risk factors for follow-up interruption of HIV patients in French Guiana. Am J Trop Med Hyg 2006; 74: 915-917.

23. Roue T, Nacher M, Fior A, et al. Cervical cancer incidence in French Guiana: South American. Int J Gynecol Cancer 2012; 22: 850-853.

24. Roué T, Labbé $\mathrm{S}$, Belliardo $\mathrm{S}$, et al. Predictive factors of the survival of women with invasive breast cancer in French Guiana: the burden of health inequalities. Clin Breast Cancer 2016; 16: e113-118.

25. Jolivet A, Cadot E, Angénieux O, et al. Use of an emergency department in Saint-Laurent du Maroni, French guiana: does being undocumented make a difference? J Immigr Minor Health 2014; 16: 586-594.

26. Valmy L, Gontier B, Parriault MC, et al. Prevalence and predictive factors for renouncing medical care in poor populations of Cayenne, French Guiana. BMC Health Serv Res 2016; 16: 34.

\section{AUTHORS' CONTRIBUTIONS}

DRR prepared the resarch concept and design of the publication. DRR, JMD, RR and MM collected data. DRR, MN analysed data, wrote the article, revised the paper and finally approved it. 